Original Research Article

\title{
Cognitive and developmental assessment between breast fed and mixed fed children: a cross sectional study
}

\author{
Singh V.K ${ }^{1}$, Mittal $M^{2}$, Singh $P^{3}$, Mehta $A^{4}$, Sharma $B^{5}$, Kushwaha K.P \\ ${ }^{1}$ Dr Vijay Kumar Singh, Assistant Professor, ${ }^{2}$ Dr Mahima Mittal, Associate Professor, ${ }^{3}$ Dr Priyanka Singh, Assistant \\ Professor, ${ }^{4}$ Dr Anita Mehta, Associate Professor, ${ }^{5}$ Dr Bhoopendra Sharma, Associate. Professor, ${ }^{6}$ Dr Komal Prasad \\ Kushwaha, Professor, all authors are affiliated with Department of Pediatrics, BRD Medical College, Gorakhpur, U.P, \\ India.
}

Address for Correspondence: Dr. Vijay Kumar Singh, Assistant Professor, Department of Pediatrics, BRD Medical College, Gorakhpur, UP, India, Email id: vijaysingh.vns.04@gmail.com

\begin{abstract}
Introduction: The importance of breastfeeding for cognitive development has been researched widely over the past several decades and has been found to be associated with significantly higher scores for cognitive development than the formula feeding. Right from initial research of Hoefer and Hardy, The majority of published studies have concluded that breastfeeding has beneficial effect on cognitive development worldwide. Objective: To evaluate cognitive and developmental assessment in breastfed and mixed fed children. Design: A cross sectional study. Setting: The study was carried out in six blocks of Lalitpur district (U.P.) from June 2009- March 2010. Material \& methods: Total 705 children including (breast fed and mixed fed) were selected by percentage population allocation technique. Fisher's exact test applied as test of significance. Epi info version-7 was used for statistical calculation. Result: After analyzing total 705 children 1mo-2years of age, out of which 458 were breast fed and 247 were mixed fed, all the seventeen items used in TDSC were found to be very significant $(\mathrm{p}<0.0001)$ except Raising self to sitting position $(\mathrm{p}=0.3460)$ and Walking upstairs with help $(\mathrm{p}=0.2642)$. Conclusion: As compared to mixed fed group, exclusively breast fed children had better cognitive and developmental skill than mixed fed children. (As matched with TDSC).
\end{abstract}

Keywords: Developmental delay, Mixed fed, and TDSC scales

\section{Introduction}

The importance of breastfeeding for cognitive development has been researched widely over the past several decades and has been found to be associated with significantly higher scores for cognitive development than the formula feeding [1, 2]. Right from initial research of Hoefer and Hardy [3], the majority of published studies have concluded that breastfeeding has beneficial effect on cognitive development worldwide [4-11]. Breast milk contains a complex array of nutrients, trophic factor, and other bioactive ingredients $[12,13]$. Docosahexanoic acid is

Manuscript received: $10^{\text {th }}$ September 2016

Reviewed: $26^{\text {th }}$ September 2016

Author Corrected; $10^{\text {th }}$ October 2016

Accepted for Publication: $22^{\text {nd }}$ October 2016 abundant in human milk and rapidly incorporated into the central nervous system during the first three months of life [14-18, 19].

The act of breast feeding may also favor infant's intellectual development through increased motherinfant positive interaction resulting in better long - term relationship the association between breastfeeding and estimates of cognitive ability is consistently attenuated by adjustment for socioeconomic status and environmental factors $[1,2]$.

Despite of studies conducted worldwide very little data is available. 


\section{Aims \& Objectives}

This study was conducted to observe differences in cognitive and development skill between exclusively breast fed children and mixed fed children (age1 month2 years).

\section{Material \& Methods}

Sample size $(\mathrm{n})=(\text { confidence interval })^{2} \mathrm{p} \mathrm{q} / \mathrm{d}^{2}$

( $p=$ prevalence of disease or morbidity, $q=(1-p), d=$ permissible error (absolute precision) $c . i=1.96)$.

Sample size was calculated by sample size determination in health studies (practical manual) by S.K. Lwanga and S.Lameshow, WHO, Geneva. Taking the prevalence of developmental delay in children about 16\% [20-23] sample size of total 705 children 1 month- 2 years of age with their mothers, were selected by percentage population allocation technique in six blocks of Lalitpur. Selection of children was irrespective of sex, birth weight; breast feeding education, mother's age, mother educational status, parity, religion, duration, frequency of breast feeding and religion were matched between populations (Table - 1).

Table 1: Population characteristics.

\begin{tabular}{|c|c|c|c|}
\hline Population characteristics & Breast fed $(\mathrm{n} 1=458)$ & Mixed fed (n2=247) & $\begin{array}{c}\text { Two tailed } \\
\text { P - value }\end{array}$ \\
\hline Male & $340(74.4 \%)$ & $197(80 \%)$ & \multirow[t]{2}{*}{0.1214} \\
\hline Female & $118(25.6 \%)$ & $50(20 \%)$ & \\
\hline Mean Birth wt. $<2.5 \mathrm{~kg}$ & $258(56.3 \%)$ & $144(58.4)$ & \multirow[t]{2}{*}{0.633} \\
\hline Mean Birth wt.>2.5kg & $200(43.7 \%)$ & $103(41.6 \%)$ & \\
\hline $\begin{array}{l}\text { Adequate breastfeeding education to } \\
\text { mother }\end{array}$ & $214(46.9 \%)$ & $112(45.5 \%)$ & \multirow[t]{2}{*}{0.7518} \\
\hline $\begin{array}{l}\text { Inadequate breastfeeding education to } \\
\text { mother }\end{array}$ & $244(53.1 \%)$ & $135(54.5 \%)$ & \\
\hline \multicolumn{4}{|l|}{ Mother age at $1^{\text {st }}$ delivery } \\
\hline$<25 \mathrm{yr}$ & $268(58.6 \%)$ & $160(64.9 \%)$ & \multirow[t]{2}{*}{0.106} \\
\hline$>25 \mathrm{yr}$ & $190(41.4 \%)$ & $87(35.1 \%)$ & \\
\hline Education $>8^{\text {th }}$ standard & $270(35.9 \%)$ & $145(58.7 \%)$ & \multirow[t]{2}{*}{1.0} \\
\hline Education $<8^{\text {th }}$ standard & $188(64.1 \%)$ & $102(45.3 \%)$ & \\
\hline Parity $=<2$ & $257(56.2 \%)$ & $135(54.5 \%)$ & \multirow[t]{2}{*}{0.750} \\
\hline Parity $>2$ & $201(43.8 \%)$ & $112(45.5 \%)$ & \\
\hline \multicolumn{4}{|l|}{ General category } \\
\hline Yes & $54(11.7 \%)$ & $29(11.7 \%)$ & \multirow[t]{2}{*}{1.000} \\
\hline No & $404(89.3 \%)$ & $218(89.3 \%)$ & \\
\hline \multicolumn{4}{|l|}{ Breastfeeding initiation } \\
\hline$<1 \mathrm{hr}$ of delivery & $243(53.0 \%)$ & $140(56.6 \%)$ & \multirow[t]{2}{*}{0.383} \\
\hline$>1 \mathrm{hr}$ of delivery & $215(47.0 \%)$ & $107(43.4 \%)$ & \\
\hline \multicolumn{4}{|l|}{ Duration of breastfeeding } \\
\hline$<10$ minutes & $250(54.7 \%)$ & $135(54.5 \%)$ & \multirow[t]{2}{*}{1.000} \\
\hline$>10$ minutes & $208(45.3 \%)$ & $112(45.5 \%)$ & \\
\hline \multicolumn{4}{|l|}{ Breastfeeding Frequency } \\
\hline$<6$ times/day & $236(51.6 \%)$ & $123(59.8 \%)$ & \multirow[t]{2}{*}{0.693} \\
\hline$>6$ times/day & $222(48.4 \%)$ & $124(40.2 \%)$ & \\
\hline Hindus & $367(80.3 \%)$ & $183(74.1 \%)$ & \multirow[t]{2}{*}{0.070} \\
\hline Others & $91(19.7 \%)$ & $64(25.9 \%)$ & \\
\hline
\end{tabular}


Case definition: The "Breast fed" child means the one who is/was fed exclusively on breast milk in first six months of his/her life. The "Mixed fed" child refers to one who was either 'predominantly' or 'partially' breast fed.

Inclusion criteria: all the children who were 1 mo- 2 years of age, including breast fed \& mixed fed.

\section{Exclusion criteria:}

1. Children less than 1 months of age.

2.children with cerebral palsy, chronic diseases, physically handicapped, malnourished, mentally retarded and other neurological disorder and those who did not participate in this study.

A questionnaire containing (consent form, breastfeeding observation form, breastfeeding education form, director's guide form, dietary recall form) and TDSC in local language were used to collect the data.

Ethical issues: Ethical issues approval has been obtained by key institution, B. R. D. Medical College, Gorakhpur.

Statistics: Fisher's exact test applied as test of significance. Epi info version-7 was used for statistical calculation.

Questionnaire forms containing TDSC, the milestones of these children were assessed according to the TDSC (Trivandrum Developmental Screening Chart) in children 1mo-2 years of age.

There is an over representation of items near one year of age because one year is an ideal age for formal cognitive and developmental assessment in community setting.

Prior to fill up questionnaire forms all the ANM, ASHA and BFCHI worker were given hands on training in the use of the for questionnaire forms containing TDSC and their ability to use the TDS chart was checked repeatedly.

A vertical line is drawn, or a pencil is kept vertically, at the level of chronological age of child being tested. If child fails to achieve any item that falls short on left side of the vertical line, the child is considered to have a developmental delay. Any obvious abnormality or asymmetry is also considered as abnormal.

The ANM, ASHA and mother support groups persuaded the mother to bring children less than two years of age to the Anganwadi on specific date and time then all details were recorded on the questionnaire forms which were filled after interviewing the mothers and the screening test was administered.

Those who failed to turn up were visited at home and the screening test was administered there, thus covering all the 705 children aged less 1mo-2 years of age from all the 6 blocks of Lalitpur district were enrolled for the study. After interview to the mothers of these babies, the children were divided into two groups the exclusively breast fed group (n= $458)$ and the mixed fed group $(n=247)$.

All those children who failed any one or more test item (developmental delay) and every $10^{\text {th }}$ normal child (without developmental delay) were called to the health centre on specific date and time. Those who failed to turn up were repeatedly contacted.

Finally children found to have developmental delay on TDSC test result, those children were only TDSC test again administered by an experienced observer from the BRD Medical College, Gorakhpur, who blind to the TDSC test result on specific date and time at health center.

Then both of the groups were further divided into two subgroups, viz. normal and delayed, according to attainment or non attainment of the milestones according to age of child on TDSC test. 
Original Research Article

\section{Result}

After analyzing total 705 children less 1mo-2 years of age, out of which 458 were breast fed and 247 were mixed fed, all the seventeen items used in TDSC were found to be very significant $(\mathrm{p}<0.0001)$ except Raising self to sitting position $(\mathrm{p}=0.3460)$ and Walking upstairs with help $(\mathrm{p}=0.2642)$ Table-2

Table-2

\begin{tabular}{|c|c|c|c|c|c|}
\hline & \multicolumn{2}{|c|}{ Breastfed $\left(\mathrm{n}_{1}=159\right)$} & \multicolumn{2}{|c|}{ Mixed fed $\left(n_{2}=87\right)$} & \multirow{2}{*}{$\begin{array}{c}\text { Two tailed } \\
\text { p value }\end{array}$} \\
\hline $1 \mathrm{mo}-6 \mathrm{month}(\mathrm{N} 1=246)$ & Normal & Delayed & Normal & Delayed & \\
\hline Social smile & $139(88 \%)$ & $20(12 \%)$ & $52(60.0 \%)$ & $35(40.0 \%)$ & 0.0001 \\
\hline Eyes follow pen/pencil & $138(87.2 \%)$ & $21(12.8 \%)$ & $50(60.0 \%)$ & $37(40.0 \%)$ & 0.0001 \\
\hline Holds head steadily & $143(90 \%)$ & $16(10 \%)$ & $61(70.0 \%)$ & $26(30.0 \%)$ & 0.0001 \\
\hline Rolls from back to stomach & $118(74.4 \%)$ & $41(25.6 \%)$ & $35(40.0 \%)$ & $52(60.0 \%)$ & 0.0001 \\
\hline Transfers objects & $142(89.7 \%)$ & $17(10.3 \%)$ & $56(65.0 \%)$ & $31(35 . \%)$ & 0.0001 \\
\hline Raises self to sitting position & $118(74.4 \%)$ & $41(25.6 \%)$ & $70(80.0 \%)$ & $17(20.0 \%)$ & 0.3460 \\
\hline 6mo-1year $(\mathrm{N} 2=352)$ & \multicolumn{2}{|c|}{ Breastfed $\left(n_{3}=225\right)$} & \multicolumn{2}{|c|}{ Mixed fed $\left(n_{4}=127\right)$} & \\
\hline Standing up by furniture & $205(90.9 \%)$ & $20(9.1 \%)$ & $93(73.3 \%)$ & $34(26.7 \%)$ & 0.0001 \\
\hline Fine prehension of pellet & $205(90.9 \%)$ & $20(9.1 \%)$ & $76(60.0 \%)$ & $51(40.0 \%)$ & 0.0001 \\
\hline Pats a cake & $211(93.9 \%)$ & $14(6.1 \%)$ & $85(66.7 \%)$ & $42(33.3 \%)$ & 0.0001 \\
\hline Walks with help & $210(93.3 \%)$ & $15(6.7 \%)$ & $68(53.4 \%)$ & $59(46.6 \%)$ & 0.0001 \\
\hline Throws a ball & $195(86.7 \%)$ & $30(13.3 \%)$ & $42(33.3 \%)$ & $85(66.7 \%)$ & 0.0001 \\
\hline Walks alone & $204(90.7 \%)$ & $21(9.3 \%)$ & $42(33.3 \%)$ & $85(66.7 \%)$ & 0.0001 \\
\hline Says 2 words & $208(92.7 \%)$ & $17(7.3 \%)$ & $76(60.0 \%)$ & $51(40.0 \%)$ & 0.0001 \\
\hline (1year-2year N3=107) & \multicolumn{2}{|c|}{ Breastfed $\left(n_{5}=64\right)$} & \multicolumn{2}{|c|}{ Mixed fed $\left(n_{6}=43\right)$} & \\
\hline Walks backwards & $52(81.0 \%)$ & $12(19.0 \%)$ & $24(55.0 \%)$ & $19(45.0 \%)$ & 0.008 \\
\hline Walks upstairs with help & $50(78 \%)$ & $14(22 \%)$ & $29(70.0 \%)$ & $14(30.0 \%)$ & 0.2642 \\
\hline Points to parts of a doll & $48(75.0 \%)$ & $16(25.0 \%)$ & $15(35.0 \%)$ & $28(65.0 \%)$ & 0.0001 \\
\hline
\end{tabular}

\section{Discussion}

The rationale of this study was to determine the cognitive \& developmental assessment in breastfed babies and mixed fed babies and to find if there is any significant correlation between exclusive breast feeding and cognitive development of the baby. The secondary objective was to promote, support \& strengthen exclusive breastfeeding, with the help of ICDSs, AWWs \& mothers support groups. The reason for selection of this district was based on poor development indicators [24]. During the study, cognitive and developmental assessment was based on the TDSC (Trivandrum Developmental Screening Chart) for 1mo2 year children. As assessed in this study, there are significant differences in children's physical and mental growth when they are breast fed or mixed fed.
It was found that the children's development was delayed more when they were not exclusively breast fed. Higher IQ connected to breastfeeding; there are two studies summarizing the findings of the Christchurch School of Medicine in New Zealand, which followed 1,000 children for 18 years to establish the relationship between intelligence and breast feeding, it was concluded that breastfeeding is associated with small but detectable increases in child cognitive ability and educational achievement. [33]. other studies that also show a correlation between breastfeeding and cognitive development [11, 25- 26, 31]. Lucas, A. et al. Breast milk and subsequent intelligence quotient in children born preterm; Formula-fed preterm infants had lower IQ scores at age 7-8 years than preemies fed 
expressed breast milk; the association held after controlling for mother's education and social class, and regardless of whether the mother attempted to express milk and failed or never attempted to express milk.

Kramer et al. found that prolonged and exclusive breast-feeding improves cognitive development as measured by IQ and teachers' academic ratings in children at age 6.5 years, according to the results of the largest randomized trial ever conducted in the area of human lactation $[5,9,11]$.

"The evidence that breastfeeding improves cognitive development is based almost entirely on observational studies and is thus prone to confounding by subtle behavioral differences in the breastfeeding mother's behavior or her interaction with the infant," write Michael S. Kramer and colleagues from the Promotion of Breastfeeding Intervention Trial (PROBIT) Study Group.

The goal of this cluster-randomized trial was to determine whether prolonged and exclusive breastfeeding was associated with improved cognitive ability in children at age 6.5 years. The breast-feeding promotion intervention was modeled on the BabyFriendly Hospital Initiative by the World Health Organization and United Nations Children's Fund (UNICEF) [27, 28].

Primary outcomes were subtest and IQ scores on the Wechsler Abbreviated Scales of Intelligence (WASI), and teacher evaluations of academic performance in reading, writing, mathematics, and other subjects.

Compared with the control group, the intervention group had a large increase in exclusive breast-feeding at age 3 months $(43.3 \%$ vs $6.4 \% ; P<.001)$ and a significantly higher prevalence of any breast-feeding at all ages, up to and including 12 months.

Compared with the control group, the intervention group had higher means on all of the WASI measures. Cluster-adjusted mean differences were +7.5 (95\% confidence interval $[\mathrm{CI}], 0.8$ - 14.3) for verbal IQ, +2.9 $(95 \% \mathrm{CI},-3.3$ to +9.1$)$ for performance IQ, and +5.9 $(95 \% \mathrm{CI},-1.0$ to +12.8$)$ for full-scale IQ.
For both reading and writing, teachers' academic ratings were significantly higher in the experimental group.

"These results, based on the largest randomized trial ever conducted in the area of human lactation, provide strong evidence that prolonged and exclusive breastfeeding improves children's cognitive development, " the study authors write. The major study limitation is lack of blinding of the pediatricians who administered the WASI to the experimental vs control intervention status of the children they examined. Several other studies have been also stated that exclusive Breastfeeding Improves Neurological functions and cognitive Development [29-33].

In our study 458 children were/had exclusively breast fed in first six months of their lives while 247 children were not exclusively breast fed, but were given mixed feeding. After interviewing the mothers of children under study, and filling the questionnaire form, we counseled all the mothers about the benefits and techniques of breast feeding and initiation of complementary feeding. For this purpose, we also took the help of ANM, ASHA and other BFCHI workers. In the one year period of study these mothers were regularly followed up on specific date and time and screening test was administered. Those who failed to turn up were visited at home and screening test administered there and were counseled on every visit.

"The evidence that breastfeeding improves cognitive development is based almost entirely on observational studies and is thus prone to confounding by subtle behavioral differences in the breastfeeding mother's behavior or her interaction with the infant," writes Michael S. Kramer, MD, and colleagues from the Promotion of Breastfeeding Intervention Trial (PROBIT) Study Group. Regression adjustment for maternal and other factors associated with breastfeeding reduces the associations between breastfeeding and cognitive or educational outcomes.

Achieving the secondary objective of the study: A project named 'Baby Friendly Community Health Initiative' (BFCHI) is already being implemented by the Department of Paediatrics, BRD Medical College, and Gorakhpur in Lalitpur district (UP). The project started in November, 2006 with an overall objective to 
test a district-based model for promoting optimal infant and young child feeding practices.

Limitations of this study are:

1. Smaller sample size

2. Besides feeding, several other factors work for cognitive development of child viz. socio-economic status, parental education, malnutrition, family environment, inadequate stimulation, and emotional factors.

\section{Conclusion}

A screening test should ideally be one with a high sensitivity and high specificity. Unfortunately, this is frequently not possible. A screening test with a high sensitivity and a gold standard test with a high specificity is what usually accepted.

In case of developmental delay there is no harm in ignoring out borderline cases particularly because large scale community intervention programs are still not available. Hence we prefer high specificity. In case of developmental delay it is difficult to get an ideal gold standard screening test. Every possible effort was taken to avoid bias in this study. Uniform hands on training were given to all ANM, ASHA and BFCHI workers. The observer who administered and interpreted the TDSC did not know the screening test result. The TDSC test had a sensitivity of $66.7 \%$ and specificity of $78.8 \%$

In this study there was significant difference in cognitive \& developmental milestones between breastfed \& mixed fed babies up to two years of age. The other possible reasons for this may be because of multi-factorial association of child's development (such as poverty, parent's education, malnutrition, medical problems, family environment,etc.).

Acknowledgements: The authors wish to express their gratitude to Mr. Praveen Dubey, coordinator (BFCHI) and his colleagues for their contribution in data collection and making easy asses in villages in Lalitpur district.

The work presented in this paper is a part of the programmed entitled 'Promotion of Baby Friendly Health Initiative' sponsored by UNICEF and the Government of U. P run under the supervision of
Department of Pediatrics, B. R. D. Medical College, Gorakhpur.

\section{Funding: Nil, Conflict of interest: Nil Permission from IRB: Yes}

Disclaimer: The views expressed in this paper are those of the authors and do not necessarily reflect the official position of the institution they are affiliated with.

\section{References}

1. Pérez-Escamilla R, Lutter C, Segall AM, Rivera A, Treviño-Siller S, Sanghvi T. Exclusive breast-feeding duration is associated with attitudinal, socioeconomic and biocultural determinants in three Latin American countries. J Nutr. 1995 Dec;125(12):2972-84.

2. Anderson JW, Johnstone BM, Remley DT. Breastfeeding and cognitive development: a meta-analysis. Am J Clinical Nutrition 1999;70(4):525-535.

3. Hoefer C, Hardy MC. Later Development of Breast Fed and Artificially fed Infants. J Am Med Assoc. 1929; 92: 615-620.

4. Auested N, scott DT, janowsky JS; Visual, Cognitive, and Language Assessments at 39 months: A follow up study of children Fed Formulas containing Long Chain Polyunsaturated fatty acids to 1 year of age. Pediatrics. 2003; 112(3): 177-183.

5. Horwood LJ, Fergusson DM. Breastfeeding and later cognitive and academic outcomes. Pediatrics. 1998 Jan;101(1):E9.

6. Angelsen NK, Vik T, Jacobsen G, Bakketeig LS. Breast feeding and cognitive development at age 1 and 5 years. Arch Dis Child. 2001; 85(3):183-8.

7. Foo LL(1), Quek SJ, Ng SA, Lim MT, DeurenbergYap M. Breast feeding prevalence and practices among Singaporean, Chinese, Malay and Indian mothers. Health Promotion International. 2005; 20 (3): 229-237.

8. Kogan MD(1), Singh GK, Dee DL, Belanoff C, Grummer-Strawn LM: Multivariate Analysis of State Variation in Breast feeding Rates in United States;Aug 13, 2008 - Am J Public Health. 2008 Oct; 98(10):187280. doi: 10.2105/AJPH.2007.127118. 
9. Kramer MS(1), Aboud F, Mironova E, Vanilovich I, Platt RW, Matush L, Shapiro S;Breast feeding and Child Cognitive Development: New Evidence from a Large Randomized Trial. Arch Gen Psychiatry. 2008 May; 65(5):578-84. doi: 10.1001/archpsyc.65.5.578.

10. Golding J, Rogers IS, Emmett PM. Association between breast feeding, child development and behaviour. Early Hum Dev. 1997 Oct 29;49 Suppl: S175-84.

11. L J Horwood, B A Darlow, N Mogridge.Breast milk Feeding and Cognitive Ability at 7-8 years. Arch Dis Child Fetal Neonatal Ed. 2001;84:F23-F27 doi:10. 1136/fn.84.1.F23-7

12. Dewey KG. Nutrition, Growth, and complementary feeding of the breast fed infant. Pediatr Clin North Am. 2001; 48: 87-104.

13. Eileen E Birch, Dennis Hoffman, Yolanda S Castañeda, Rcardouauy:A Randomized Control Trial of early dietary supply of long chain poly unsaturated fatty acids and mental development in term infants after weaning at 6 weeks of age. Am J Clin. Nutr. 2002; 75 (3): $570-580$.

14. Reynolds A. Breast feeding and Brain Development. Pediatr Clin North Am. 2001; 48: 159171.

15. Birch EE, Hoffman DR, Uauy R, Birch DG, Prestidge C. Visual acuity and the essentiality of docosahexaenoic acid and arachidonic acid in the diet of term infants. Pediatr Res. 1998;44(2):201-209.

16. Susan E. Carlson, Richard J. Cooke, Susan H. Werkman, Elizabeth A. Tolley; First year growth of pre term infants fed standard compared to marine oil n3 supplemented formula. Lipids (1992) 27: 901. doi: 10.1007/BF02535870.

17. Innis SM, Adamkin DH, Hall RT, Kalhan SC, Lair C, Lim M. Docosahexanoic acid and arachidonic acid enhance growth with no adverse effects in preterm infants fed formula. J Pediatr 2002; 140: 547-554.

18. Lucas A, Stafford M, Morley R, Abbott R, Stephenson T, MacFadyen U. Efficacy and safety of long-chain polyunsaturated fatty acid supplementation of infant-formula milk: a randomized trial. Lancet 1999; 354: 1948-1954.

19. Martinez M: Tissue levels of polyunsaturated fatty acids during early human development. J Pediatr 1992; 120:S129-S138.

20. Developmental Surveillance and screening of infants and young children. American Academy of Pediatrics, Committee on children with disabilities. Pediatrics 2001; 108: 192-196.

21. Sally Grantham-McGregorion, Yin Bun Cheung, Santiago Cueto, Paul Glewwe, Linda Richter, Barbara Strupp, Developmental potential in first 5 years for children in developing countries. Lancet 2007; 369: No. 9555; 60-70.,

22. Walker SP, Wachs TD, Gardener JM, Lozoff B, Wasserman GA, Pollitt E, Carter JA. International Child Development Steering Group.Child development: Risk factors for adverse outcomes in developing countries. Lancet. 2007; 369:145-157.

23. Engle PL, Black MM, Behrman JR. International Child Development Steering Group: Strategies to avoid the loss of developmental potential in more than 200 million children in the developing world. Lancet. 2007; 369:229-242. doi: 10.1016/S0140-6736(07)60112-3.

24. BFCHI Project-till December,2010 and Reaching the under $2 S$ (universalizing delivery of nutrition in distric Lalitpur,UP)

25. Asnat Walfisch, Corey Sermer, Alex Cressman, Gideon Koren. Breast milk and cognitive developmentthe role of confounders: a systematic review BMJ Open. 2013; 3(8): e003259. Published online 2013 Aug 22.doi: 10.1136/bmjopen-2013-003259.

26. Der G, Batty GD, Deary IJ. Effect of breast feeding on intelligence in children: prospective study, sibling pairs analysis, and meta-analysis. BMJ 2006;333:945-1 [PMC free article] [PubMed]

27. Lucas A, Morley R, Cole TJ, et al. Breast milk and subsequent intelligence quotient in children born preterm. Lancet 1992;339:261-4 
28. WHO, 2002. Benefits of exclusive breast feeding Healthy mothers and healthy babies.

29. BPNI. Breast feeding for child survival, health and development. Power point presentation by Dr. Arun Gupta at State Secretaries Meeting, Govt. of India, New Delhi. Slides available at website wcd.nic.in/statewcd.

30. Bouwstra H. Boersma ER. Boehm G; Exclusive breastfeeding of healthy term infants for at least 6 weeks improves neurological condition. J Nutr. 2003; 133:4243-5
31. Rogan WJ and Gladen BC. Breastfeeding and Cognitive Development. Early Human Development. 1993; 31: 181-193.

32. Morrow-Tlucak M, Haude RH, Ernhart CB. Breastfeeding and cognitive development in the first 2 years of life. Soc Sci Med. 1988:26;635-639

33. Neil R. Wigg,Shilu Tong,Anthony J. McMichael Peter A. Baghurst, Graham Vimpani, Russell Roberts; Breast feeding at 6 months predict cognitive development. Australian and New Zealand Journal of Public Health. 1998; 22:232-236. DOI: 10.1111/j.1467842X. 1998.tb01179.x

\section{How to cite this article?}

Singh V.K, Mittal M, Singh P, Mehta A, Sharma B, Kushwaha K.P. Cognitive and developmental assessment between breast fed and mixed fed children: a cross sectional study. Int. J PediatrRes.2016;3(10):763-770.doi:10.17511/ ijpr. 2016.i10.09 